\title{
A SEQÜÊNCIA VULCANOSSEDIMENTAR DO GRUPO NOVA LIMA NA REGIÃO DE PIEDADE DO PARAOPEBA, BORDA OESTE DO QUADRILÁTERO FERRÍFERO, MINAS GERAIS
}

\author{
CARLOS M. NOCE*, STELAMARIS O. PINHEIRO*, EDUARDO A. LADEIRA**, CLÁUDIA R. FRANCA*** e \\ SENIRA KATTAH
}

\begin{abstract}
THE VOLCANO-SEDIMENTARY SEOUENCE OF THE NOVA UMA GROUP, PIEDADE DO PARAOPEBA REGION, WESTERN BORDER OF THE QUADRILÁTERO FERRÍFERO. Piedade do Paraopeba is located at western Quadrilátero Ferrifero, where a $15 \mathrm{~km}$ long tectonic slice of Nova Lima Group rocks are stacked between the gneissic rocks of the Bonfim Complex and the basal Minas Supergroup formation (the Moeda Quartzite). The southern part of the Nova Lima sequence consists of ultramafic and mafic metavolcanics with local preserved pillow structures, minor felsic metavolcanics, metachert and thin carbonate and oxide iron formation. This sequence grades northwards to an interlayered sequence of carbonaceous phyllites, quartz-mica schists, volcanoclastic metarenites, and iron formation. The metavolcanic rocks underwent intense metassomatic alteration. Chemical analyses show that the ultramafic rocks are probably former komatiitic peridotites while the upper mafic rocks are tholeitic basalts. A polyphasic structural evolution has been distinguished in the area. The main deformation phase (Dn) led to basal thrusts with a W-NW tectonic transport.
\end{abstract}

Keywords: Greenstone belt, Quadrilátero Ferrifero, Minas Gerais.

\begin{abstract}
RESUMO A faixa do Grupo Nova Lima na região de Piedade do Paraopeba, no limite oeste do Quadrilátero Ferrifero, ocorre tectonicamente posicionada entre as rochas gnáissicas e granitóides do Complexo Bonfim e o Quartzito Moeda, formação basal do Supergrupo Minas. Sua dimensão no sentido N-S é da ordem de $15 \mathrm{~km}$. A porção sul da faixa é composta por meta vulcanites ultramáficos e máficos, localmente com estruturas em almofada preservadas, metavulcanitos félsicos muito subordinados, metachert e delgadas camadas de formação ferrífera fácies oxido e carbonato. Este pacote grada para o norte para uma seqüência interestratificada de filitos carbonosos, quartzo-mica xistos, metarenitos vulcanoclásticos e formação ferrífera. As rochas metavulcânicas incluem tipos petrográficos variados, revelando um intenso metassomatismo. Análises químicas de metavulcanitos ultramáficos demonstraram afinidades com os peridotitos komatí́ticos. As metavulcânicas máficas, que aparentemente constituem o topo da seqüência, representariam basaltos tolefticos. A análise estrutural, baseada em critérios geométricos e de superimposição, revelou uma evolução policíclica complexa. A fase principal, designada Dn, associam-se extensos cavalgamentos basais, como o do contato inferior do Supergrupo Minas, com direção de transporte para W-NW e responsáveis pela estrutura imbricada da área.
\end{abstract}

Palavras-chaves: Greenstone belt, Quadrilátero Ferrifero, Minas Gerais.

INTRODUÇÃO O presente trabalho teve como objetivo principal o estudo da seqüência vulcanossedimentar do Grupo Nova Lima na região de Piedade do Paraopeba, borda oeste do Quadrilátero Ferrifero (Fig. 1). O Grupo Nova Lima forma aí uma pequena faixa, com cerca de $15 \mathrm{~km}$ de comprimento no sentido N-S e $5 \mathrm{~km}$ de largura média, limitada a leste, norte e noroeste por rochas do Supergrupo Minas, aflorantes nos maciços rochosos das serras da Moeda, Rola Moça e Gaivotas. A oeste e sul, as rochas do Grupo Nova Lima estão em contato com gnaisses e granitóides do Complexo Bonfim.

TRABALHOS ANTERIORES O Grupo Nova Lima, no Quadrilátero Ferrifero, foi originalmente definido por Dorr et al (1957). Ladeira (1980) propôs a divisão informal do Grupo Nova Lima em três unidades, da base para o topo:

Unidade Metavulcânica Rochas ultramáficas basais formando derrames e corpos intrusivos (serpentinitos, esteatitos, talco xistos), metabasaltos (clorita-tremolita-actinolita xistos), delgadas camadas de formação ferrífera do tipo Algoma, metachertes, filitos carbonosos, meta-riolitos subordinados (quartzo-sericita xistos) e xistos tufáceos. Localmente, os vulcanites máficos e ultramáficos apresentam estruturas pillow deformadas com margens variolíticas (Ladeira 1981) e textura spinifex (Schorscher 1978, Ladeira et al 1983). A composição química destas rochas varia de komatiítica a toleítica.
Unidade Metassedimentar Química Chertes ferríferos e carbonáticos, BIF (fácies carbonato, sulfeto, silicate e oxido), intercalados com filitos carbonosos e xistos tufáceos félsicos a intermediários.

Unidade Metassedimentar Clástica Quartzo-mica xistos, xistos carbonáticos, metagrauvacas, quartzitos imaturos, metaconglomerados.

As referências sobre a faixa do Grupo Nova Lima na região de Piedade do Paraopeba são raras na literatura. O mapeamento 1:25.000 da folha homônima não foi realizado durante o projeto DNPM-USGS. A primeira referência publicada sobre as rochas ígneas da região deve-se a Godoy (1957), que as denominou de intrusivas-eruptivas básicas. Pomerene (1964) destaca o fato de que o Quartzito Moeda assenta-se em discordância estrutural por sobre as rochas do Grupo Nova Lima, tanto a leste na Serra da Moeda como a oeste na Serra das Gaivotas. Um estudo da região onde se insere a faixa de Piedade do Paraopeba é apresentado por Pires (1979), que discute um modelo de evolução para a complexa estrutura representada pela junção das estruturas das serras da Moeda e do Curral. Este autor ressalta o intenso tectonismo do contato Nova Lima/ Moeda, e considera a faixa greenstone de Piedade do Paraopeba como uma escama de empurrão. Drake \& Morgan (1980) ressaltam o intenso cisalhamento ao longo do contato entre rochas do Grupo Nova Lima e gnaisses, observado na estrada 


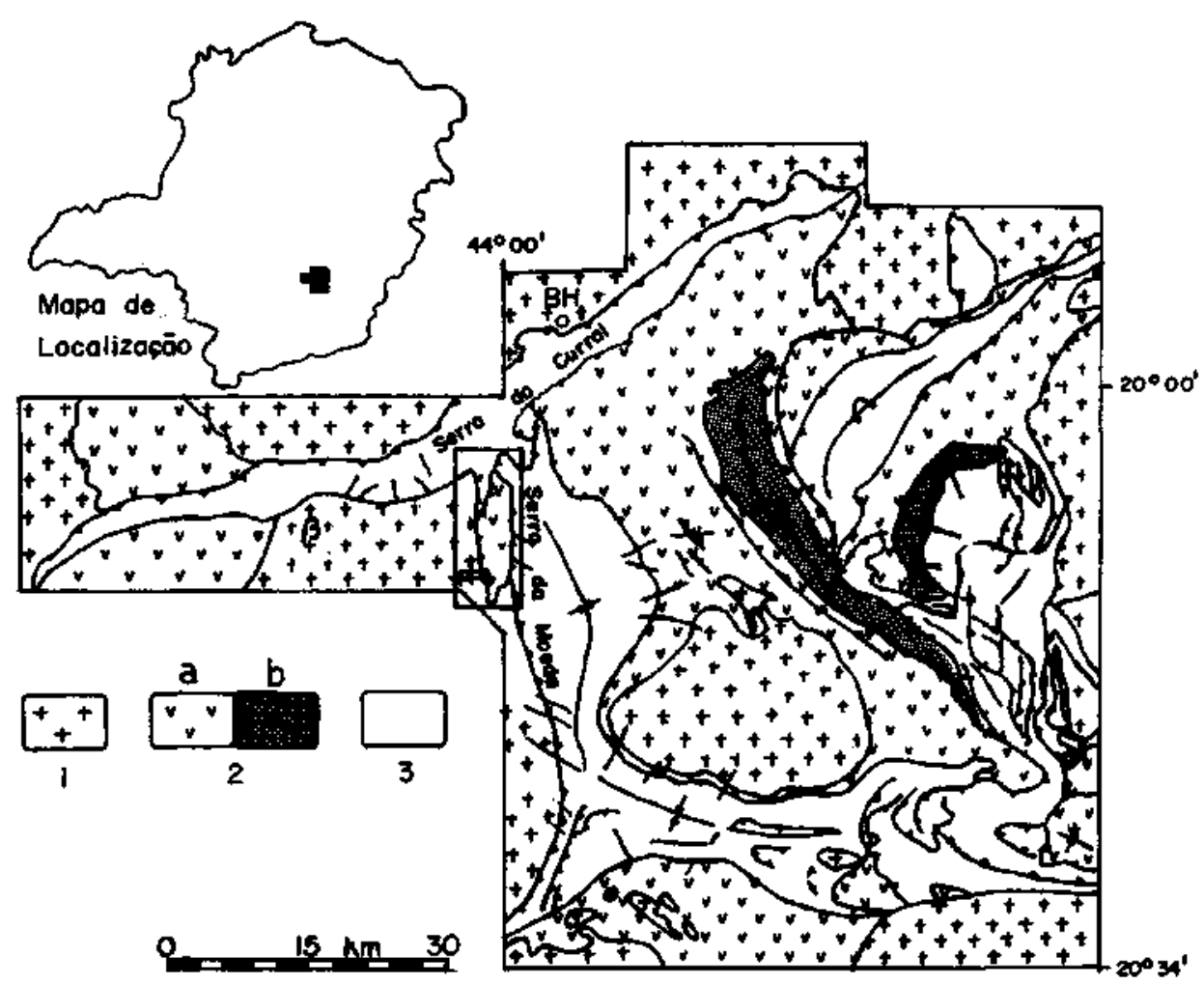

Figura 1- Mapa geológico do Quadrilátero Ferrifero (modificado de Dorr 1969) e localização da área estudada. 1. Rochas gnáissicas e granitóides; 2. Supergrupo Rio das Velhas (2a. Grupo Nova Lima; 2b. Gnipo Maquine); 3. Supergrupo Minas. BH Belo Horizonte, PP - Piedade do Paraopeba, B-Brumadinho

Figure 1 - Geologic map of the Quadrilátero Ferrífero (modified from Dorr 1969) and studied area location. 1. Gneisses and granitoids; 2. Rio das Velhas Supergroup (2a. Nova Lima Group; 2b. Maquine Group); 3. Minas Supergroup. BH - Belo Horizonte, PP - Piedade do Paraopeba, B - Brumadinho

para Piedade do Paraopeba. OIGA (1982) representa a faixa de Piedade do Paraopeba no mapa 1:50.000 da Folha Brumadinho, destacando a presença das rochas ultramáficas. Uma referência à ocorrência aurífera conhecida por Mina do Carrapato é encontrada em Lyrio (1977) e Ladeira (1988). Trabalho não publicado de Ladeira et al. (1985) sugere uma estratigrafia vulcano-sedimentar para a área da Mina do Carrapato, aqui adotada e ampliada para o restante da região. Parte da área abordada neste trabalho foi mapeada na escala 1:25.000 por Guimarães et al (1988).

ESTRATIGRAFiA E PETROgRAFiA O Grupo Nova Lima na faixa de Piedade do Paraopeba é constituído por uma seqüência essencialmente vulcânica máfica-ultramáfica a sul, gradando, lateral e verticalmente, para uma seqüência metassedimentar a norte (Fig. 2). O empilhamento estratigráfico original, no âmbito de cada uma destas distintas seqüências rochosas, foi muito obliterado pela deformação. Os sucessivos eventos deformativos provocaram a intensa transposição das estruturas planares primárias e, possivelmente, a repetição de camadas por cavalgamento e dobramento apertado. Os litotipos do Grupo Nova Lima, na região, apresentam paragêneses metamórficas características de grau baixo ou fácies xisto verde (zona da clorita).

Seqüência metavulcânica Um perfil realizado ao longo dos córregos Piedade e Carrapato sugere uma certa ordenação estratigráfíca da seqüência metavulcânica. Na base (?) predominam os derrames ultramáficos, com freqüentes intercalações máficas, níveis de metacherte e algumas intercalações de vulcânicas félsicas subordinadas. Pelo menos um corpo hipabissal (soleira?) de composição máfica foi identificado. Para o topo, até o contato com o Quartzito Moeda do Supergrupo Minas, passam a predominar os derrames máficos, igualmente com a intercalação de vulcânicas félsicas muito subordinadas. Estas rochas félsicas apresentam, em geral, espessura de poucos metros, excepcionalmente atingindo cerca de $30 \mathrm{~m}$. Formações ferríferas delgadas, centimétricas a decimétricas, de fácies oxido e carbonato, são mais freqüentes na porção superior da seqüência. Pode-se observar, em metavulcanitos ultramáficos, estruturas em almofada (Foto 1), com dimensões da ordem de 30 a $50 \mathrm{~cm}$, e que se encontram achatadas segundo a foliação. A análise petrográfica de um dos afloramentos com estrutura em almofada revelou uma rocha composta por talco, tremolita, serpentina e opacos. O material interpillow apresenta uma coloração mais clara, possuindo a mesma composição mineralógica, enriquecida em minúsculos cristais de epídoto. A preservação da estrutura em almofada é um fenômeno muito local. Por outro lado, os metavulcanitos máfico-ultramáficos exibem, freqüentemente, um bandamento de caráter tectônico, interpretado como resultante da intensa transposição da estrutura em almofada original.

As rochas meta-ultramáflcas, predominantes na base da seqüência, são representadas por serpentinitos, talco xistos, rochas talco-carbonatadas, tremolititos, clorititos, tremolitatalco xistos, tremolita-clorita xistos e talcitos. Apesar da diversidade dos litotipos, a mineralogia é relativamente monótona, variando apenas a proporção dos minerais descritos: serpentina, talco, tremolita, clorita, carbonato, magnetita e sulfetos subordinados. Estes metaultramafitos representam metakomatítos, ainda que não tenha sido observada textura spinifex. Os metavulcanitos máficos são, principalmente, representados por quartzo-clorita xistos, somados a rochas com actinolita e epídoto. Os primeiros constituem um pacote espesso, representando a porção superior da seqüência metavulcânica. Os actinolita-epidositos, que texturalmente podem ser classificados como basaltos komatiíticos (vide descrição a seguir), tendem a se posicionar intercalados às rochas ultramáficas. Uma descrição 
petrográfica dos principais litotipos que constituem a seqüência metavulcânica é apresentada a seguir.

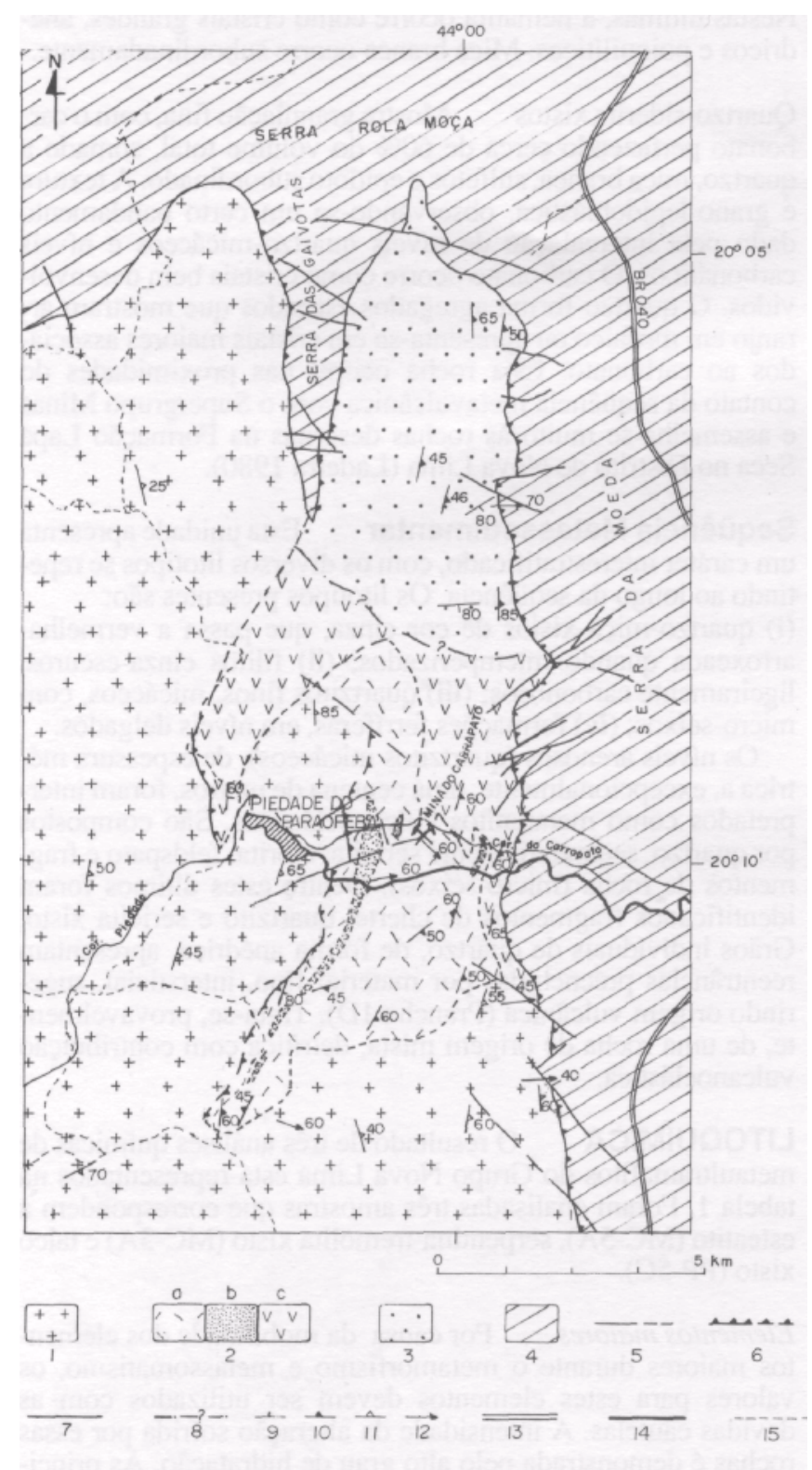

Figura 2 - Mapa geológico da região de Piedade do Paraopeba. 1. Gnaisses e granitóides; 2 e 3. Grupo Nova Lima; 2. Seqüência Metavulcânica (2a. predomínio de meíavulcânicas ultramáficas; $2 \boldsymbol{b}$. metavulcânicas félsicas; 2 c predomínio de metavulcânicas máficas); 3. Seqüência Metassedimentar; 4. Siipergrupo Minas. Símbolos geológicos; 5. contato geológico, tracejado quando inferido; 6. falha de empurrão, tracejada quando inferida; 7. falha indiscriminada; 8. contato transicional suposto; 9. acamamento $\left(S_{0}\right) ; 10$. foliação principal $\left(S_{n}\right)$; 11. foliação gnáissica elou foliação milonítica; 12. lineação de estiramento elou lineação mineral. Símbolos cartográficos: 13. rodovia; 14. estrada pavimentada; 15. estrada não-pavimentada

Figure 2 - Geologic map of the Piedade do Paraopeba region. 1. gneisses and granitoids; 2 and 3. Nova Lima Group; 2. metavolcanic sequence (2a. mainly mafic metavolcanic rocks); 3. metasedimentary sequence; 4 . Minas Supergroup. Symbols: 5. contact, dashed where inferred; 6 . thrust fault, dashed where inferred; 8. transicional contact; 9. bedding $\left(\mathrm{S}_{0}\right) ; 10$. main foliation $\left(\mathrm{S}_{\mathrm{n}}\right) ; 11$. gneissic foliation and/or milonitic foliation; 12. stretching lineation and/or mineral lineation; 13. highway; 14. paved road; 15. unpaved road

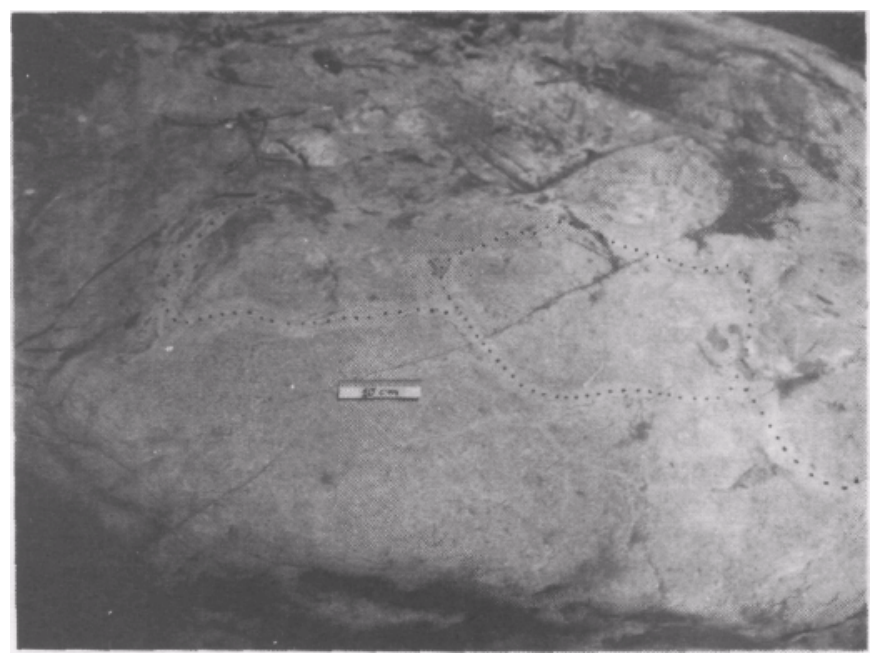

Foto 1 - Estrutura almofadada (pillows) em rocha metavulcânica ultramáfica do Grupo Nova Lima, Córrego do Carrapato. As almofadas estão parcialmente delineadas por pontilhado

Photo 1 - Nova Lima Group ultramafic metavolcanic rock showing pillow structure, located at Córrego do Carrapato. Pillows partially delineated by doted lines

METAVULCANITOS ULTRAMAFICOS Serpentinitos são rochas constituídas por 60 a $90 \%$ de serpentina com textura predominante não pseudomórfica inteipenetrativa, por vezes foliada, segundo a classificação de Wicks \& Whittaker (1977). Em raros casos, pode-se identificar prováveis relictos de cumulus de olivina, delineados por diminutos cristais de opacos. A serpentina predominante é a antigorita. A magnetita ocorre em proporções de 5 a $10 \%$, disseminada na rocha. Talco e carbonato ocorrem em vênulas. Tremolita, clorita e, mais raramente, sulfetos, também podem aparecer em quantidades subordinadas.

Rochas talco-carbonatadas São originadas por processos metassomáticos atuantes em serpentinitos (Prancha 1A). Normalmente, apresentam estrutura maciça, mas uma foliação local pode ser observada. São constituídas por cerca de 40 a $45 \%$ de talco e 50 a $55 \%$ de magnesita, com clorita e opacos subordinados. O talco ocorre como feixes de pequenos cristais $\mathrm{e}$, mais raramente, como cristais bem desenvolvidos. O carbonato apresenta-se como cristais de dimensões variáveis, dispersos em toda a rocha ou como agregados de pequenos cristais subédricos ou, ainda, sob a forma de venulações com talco associado. Uma variação deste litotipo apresenta proporções relativamente altas (até $8 \%$ ) de clorita, com pequenos cristais de sulfetos orientados segundo a foliação. Também estão presentes os esteatitos, entendidos como rochas talco-carbonatadas exibindo quantidades significativas de serpentina (10 a 45\%). A serpentina ocorre em nódulos reliquiares, com textura não pseudomórfica interpenetrativa. A clorita é menos abundante e os opacos são representados, principalmente, por magnetita.

Talco xistos e talcitos Constituem-se, essencialmente, de talco que pode atingir até $95 \%$ da rocha. Estas rochas aparecem associadas aos esteatitos, com quantidades significativas de serpentina intersticial. Apresentam textura lepidoblástica, com clorita e opacos subordinados. A clorita, na maioria dos casos, apresenta-se na mesma fase do talco.

Clorititos Apresentam granulação fina, constituídos por cerca de 60 a $85 \%$ de clorita com magnetita ou "leucoxênio" 
em proporções variáveis. Epídoto e talco são subordinados. Texturalmente, os clorititos são subdivides em dois tipos, um com textura lepidoblástica bem desenvolvida e outro maciço.

Tremolititos e tremolita xistos São rochas de granulação fina, compostas por tremolita $(50$ a $80 \%)$, clorita (2 a $30 \%)$, talco (0 a 40\%), com quantidades subordinadas de carbonato e opacos. Apresentam dois tipos texturais: lepidonematoblástica e não orientada.

METAVULCANITOS MÁFICOS Actinolita-epidositos rochas de estrutura maciça, granulação fina, constituída por actinolita, epídoto e clinozoisita, quartzo e quantidades menores de clorita e opacos. Dois aspectos texturais destacamse nestas rochas: feixes de cristais de actinolita com forma semi-radiada e cristais de formas esqueléticas (textura hollow? -Prancha 1A). Os cristais de formas esqueléticas são de anfibólio, caracterizados por formas irregulares com cavidades, encontrando-se imersos numa matriz fina de actinolita, epídoto e quartzo. Os grandes cristais de anfibólio perfazem de 15 a $20 \%$ da rocha e são pseudomórficos sobre grãos de piroxênio e/ou olivina. Estas características texturais, aliadas a ausência de titanita, indicam que esta rocha pode representar um metabasalto komatiítico.

Quartzo-clorita xistos São as rochas mais abundantes de composição básica. Possuem granulação fina e foliação bem desenvolvida. São compostas, principalmente, por clorita, quartzo e pequenas quantidades de minerais opacos. Sericita pode ocorrer subordinadamente, excepcionalmente perfazendo até $20 \%$ da rocha. Turmalina e epídoto são acessórios comuns. A textura é normalmente lepidoblástica, adquirindo um aspecto milonítico próximo do contato com o Supergrupo Minas, onde são freqüentes as remobilizações de quartzo.

METAVULCANITOS FÉLSICOS Em termos petrográficos, constituem quartzo-sericita xistos, com textura blastoporfirítica, os fenocristais perfazendo cerca de 8 a $10 \%$ do volume total e constituídos por quartzo (cerca de 70\%) e plagioclásio sódico $(30 \%)$. Os aspectos texturais variam em função do grau de deformação que afetou a rocha. Nas rochas menos deformadas, os fenocristais de quartzo são euédricos, com formas bipiramidais e dimensão média da ordem de 0,5 a 2,0 mm. Grãos de formas amebóides são interpretados como originados devido a processos de reabsorção magmática. Os fenocristais de plagioclásio estão presentes nas rochas menos deformadas; apresentam formas anédricas com bordos corroídos e estão sericitizados (Prancha 1C). Geminações polissintéticas associadas à dupla geminação da lei da Albita e Carlsbad indicam a origem ígnea para estes grãos. A matriz é constituída por um agregado muito fino de quartzo, sericita e quantidades subordinadas de carbonato. A sericita forma, por vezes, placas mais desenvolvidas, principalmente nos locais onde envolvem os fenocristais de quartzo e feldspato. Nas rochas mais intensamente deformadas, a textura lepidoblástica adquire aspecto milonítico. Os fenocristais de quartzo passam a apresentar sombras de pressão com recristalização nos bordos e texturas pull-apart. Quanto maior a recristalização menos freqüentes são os fenocristais de feldspato. A matriz se torna mais recristalizada, mostrando textura grano-lepidoblástica. Os aspectos texturais, assim como a constituição mineralógica destes xistos, indicam que eles são resultantes do metamorfismo de rocha vulcânica de natureza riodacítica.

FORMAÇÕES FERRÍFERAS Ocorrem como intercalações nos quartzo-clorita xistos, em níveis de espessura decimétrica e sem continuidade lateral, sendo classificadas como formações ferríferas do tipo Algoma. Duas variedades de formação ferrífera são encontradas:
Formações ferríferas bondadas São constituídas, essencialmente, pela alternância de bandas milimétricas ricas em quartzo, com arranjo em mosaico, e bandas ricas em hematita. Nestas últimas, a hematita ocorre como cristais grandes, anédricos e poiquilíticos. Mica branca ocorre subordinadamente.

Quartzo-siderita xistos Mostra granulação fina, com o carbonato perfazendo cerca de $60 \%$ do volume total, somado a quartzo, mica branca, sulfetos e epídoto subordinado. A textura é grano-lepidoblástica, observando-se um certo bandamento dado pela intercalação de níveis quartzo-micáceos e níveis carbonáticos. $\mathrm{O}$ carbonato ocorre como cristais bem desenvolvidos. O quartzo forma agregados estirados que mostram arranjo em mosaico ou apresenta-se em cristais maiores associados ao carbonato. Esta rocha ocorre nas proximidades do contato da seqüência metavulcânica com o Supergrupo Minas e assemelha-se muito às rochas descritas na Formação Lapa Seca no Distrito de Nova Lima (Ladeira 1980).

Seqüência Metassedimentar Esta unidade apresenta um caráter interestratificado, com os diversos litotipos se repetindo ao longo da seqüência. Os litotipos presentes são: (i) quartzo-mica xistos de cor cinza, que passa a vermelhaarroxeada quando intemperizados; (ii) filitos cinza-escuros, ligeiramente carbonosos; (iii) quartzitos finos, micáceos, com micro-seixos; (iv) formações ferríferas, em níveis delgados.

Os níveis arenosos (quartzitos micáceos), de espessura métrica a, excepcionalmente, uma centena de metros, foram interpretados como metarenitos vulcanoclásticos. São compostos por quartzo, secundariamente sericita, clorita, feldspato e fragmentos de rocha (micro-seixos). Dentre estes últimos foram identificados fragmentos de cherte, quartzito e sericita xisto. Grãos individuais de quartzo, de forma anédrica, apresentam reentrâncias preenchidas por material fino, intersticial, sugerindo origem vulcânica (Prancha $\mathrm{ID}$ ). Trata-se, provavelmente, de uma rocha de origem mista, detrítica com contribuição vulcanoclástica.

LITOQUÍMICA O resultado de três análises químicas de metaultramafitos do Grupo Nova Lima está representados na tabela 1. Foram analisadas três amostras que correspondem a esteatito (MC-5A), serpentina-tremolita xisto (MC-5A) e talco xisto (PP-5C).

Elementos maiores Por causa da mobilidade dos elementos maiores durante o metamorfismo e metassomatismo, os valores para estes elementos devem ser utilizados com as devidas cautelas. A intensidade da alteração sofrida por essas rochas é demonstrada pelo alto grau de hidratação. As principais características das amostras analisadas são as seguintes: baixos teores de $\mathrm{SiO}_{2}$; altos teores de $\mathrm{MgO} ; \mathrm{Na}_{2} \mathrm{O}+\mathrm{K}_{2} \mathrm{O}$ baixos; razões $\mathrm{CaO} / \mathrm{Al}_{2} \mathrm{O}_{3}$ baixas.

Elementos traços Segundo Nesbitt \& Sun (1976) e Condie (1981), as razões dos elementos traços em condritos são: $\mathrm{Ti} / \mathrm{Zr}=102, \mathrm{~V} / \mathrm{Zr}=11,5, \mathrm{Zr} / \mathrm{Y}=2,5 \mathrm{e} \mathrm{Ti} / \mathrm{Y}=256$. Em muitas rochas komatíticas estudadas no mundo se observa uma proximidade das razões de $\mathrm{Ti} / \mathrm{Zr}$, Ti/Y e $\mathrm{Y} / \mathrm{Zr}$ com os valores das razões destes elementos em condritos. Nas rochas analisadas (Tab. 1) as razões $\mathrm{Ti} / \mathrm{V}$ estão próximas aos valores dos condritos, mas as razões que utilizam o $\mathrm{Zr}$ mostram valores bastante diferentes. É possível um problema de análise para este elemento.

Elementos terras raras A normalização rocha/condrito foi feita com base nos valores de Evensen et al. (1978). As duas amostras analisadas mostram um enriquecimento em terras raras leves, e o serpentina-anfibólio xisto (amostra MC-5A) evidencia uma anomalia negativa de európio (Fig. 3). A anomalia negativa de európio em rochas deste tipo está, provável- 

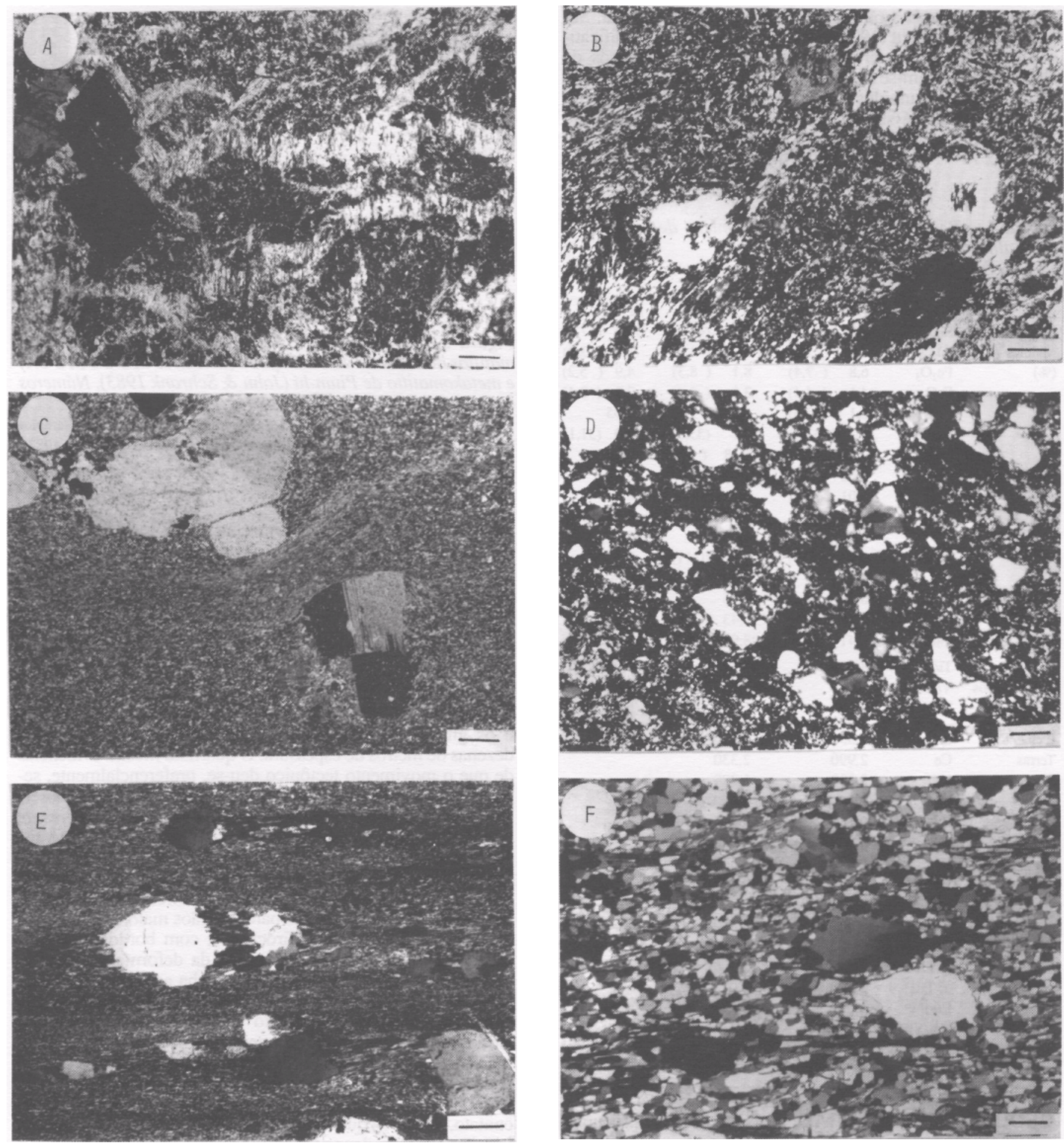

Prancha 1 - A. Serpetinito intensamente alterado, exibindo veios de talco e cristais maiores de carbonato. LP x 25; escala = $0,43 \mathrm{~mm} .3 d$. B. Metabasalto, provavelmente komatiitico. Cristais maiores de tremolita-actinolita, com textura do tipo hollow, devem representar antigos fenocristais de olivina elou piroxênio. A matriz é constituída por tremolita-actinolita, epídoto, quartzo e quantidades subordinadas de clorita e opacos. LP x 25; escala $=0,43 \mathrm{~mm}$. C Metarriodacito com textura blastoporfirítica. Os blastopórfiros são constituídos por cristais de plagioclásio exibindo dupla macia Albita e Albita/Carlsbad. LP x 25; escala $0,43 \mathrm{~mm}$. D. Metassedimento arenoso com contribuição vulcanoclástica. Alguns fragmentos de quartzo assemelham-se a shards. LP x 50; escala=0,23mm. E e F. Milonito-gnaisse (E) e milonito-quartzito (F), no contato basal da Formação Moeda, Serra da Moeda, Condomínio Retiro do Chalet. LPx25; escala $=0,43 \mathrm{~mm}$

Plate 1 - A. Highly altered serpentinite showing talc veins and large carbonate minerals. Under crossed nicols x 25, scale $=0.43 \mathrm{~mm}$. B. Metabasalt with probably komatiitic affinity. The large tremolite-actinolite crystals showing hollow texture are probably former olivine and/or pyroxene fenocrysts. Under crossed nicols $\mathrm{x} 25$, scale $=0.43 \mathrm{~mm}$. C. Metaryodacite showing blastoporphyritic texture. The former phenocrysts are plagioclases showing both Albite/Carlsbad twining. Under crossed nicols x 25 , scale $=0.43 \mathrm{~mm}$. D. Arenaceous metasediment partially volcanoclastic. Some quartz fragments are similar to shards. Under crossed nicols x 50 , scale $=0.23 \mathrm{~mm}$. E. and F. Milonite-gneiss (E) and milonite-quartzite $(\mathrm{F})$ at the basal contact of the Moeda Formation, Serra da Moeda. Under crossed nicols x 25 , scale $=0.43 \mathrm{~mm}$ 
mente, relacionada a processos de alteração hidrotermal. Segundo Sun \& Nesbitt (1978), as modificações mais significativas dos padrões de terras raras, quando dos processos de alteração, verificam-se nas terras raras leves e nas anomalias de európio. A assinatura dos elementos terras raras das rochas do presente trabalho é similar àquela obtida em metaperidotito komatiítico da região de Pium-hi (Jahn \& Schrank 1983).

Tabela 1 - Resultados das análises químicas de metavulcaniíos ultramáficos

Table 1 - Chemical analysis of ultramafic meta volcanic rocks

\begin{tabular}{|c|c|c|c|c|c|c|}
\hline \multirow{4}{*}{$\begin{array}{l}\text { Elementos } \\
\text { Maiores } \\
(\%)\end{array}$} & \multirow{4}{*}{$\begin{array}{l}\text { Amostra } \\
\mathrm{SiO}_{2} \\
\mathrm{Al}_{2} \mathrm{O}_{3} \\
\mathrm{Fe}_{1} \mathrm{O}\end{array}$} & \multicolumn{2}{|l|}{ MC.5 } & \multicolumn{2}{|c|}{ MC-5A } & PP-5C \\
\hline & & 40.7 & $(44,1)$ & 43,1 & $(47,6)$ & $53,8 \quad(57,6)$ \\
\hline & & 2,0 & $(2,2)$ & 1,6 & $(1,8)$ & $2,8 \quad(3,0)$ \\
\hline & & 6.8 & $(7,4)$ & 8.1 & $(8,3)$ & $4,9(5,2)$ \\
\hline & $\mathrm{FeO}$ & 4,1 & $(4,4)$ & 3,1 & $(3,4)$ & $2,2 \quad(2,4)$ \\
\hline & $\mathrm{CaO}$ & 3,1 & $(3,4)$ & 1,9 & $(2,1)$ & 0,05 \\
\hline & $\mathrm{MgO}$ & 30,3 & $(32,8)$ & 32,1 & $(35,5)$ & $29,0 \quad(31,1)$ \\
\hline & $\mathrm{THO}_{2}$ & 0,24 & $(0,26)$ & 0,18 & $(0,2)$ & 0,05 \\
\hline & $\mathrm{Na}_{2} \mathrm{O}$ & 0,02 & & 0,06 & $(0,07)$ & 0,01 \\
\hline & $\mathrm{K}_{2} \mathrm{O}$ & 0,01 & & 0,01 & & 0,01 \\
\hline & $\mathrm{P}_{1} \mathrm{O}_{5}$ & 0,05 & & 0,05 & & 0,05 \\
\hline & $\mathbf{s}$ & 0,01 & & 0,01 & & 0,01 \\
\hline & $\mathrm{MnO}$ & 0,13 & $(0,14)$ & 0,10 & $(0, t 1)$ & 0,04 \\
\hline & $\mathrm{CO}_{2}$ & 4,7 & & 0,10 & & 0,30 \\
\hline & $\mathrm{H}_{2} \mathrm{O}$ & 0,08 & & 0,16 & & 0,14 \\
\hline & $\mathrm{H}_{2} \mathrm{O}^{*}$ & 7,18 & & 8,43 & & 5,48 \\
\hline & total & 99,41 & & 98,94 & & 98,83 \\
\hline Razós & $T / Z \mathbf{r}$ & 48,7 & & 42,82 & & 29,97 \\
\hline de Elementos & $\mathrm{v} / \mathbf{Z} \mathbf{r}$ & 3,5 & & 3,85 & & 7,8 \\
\hline Traços & $\mathrm{TW} / \mathrm{V}$ & 13.6 & & 11.10 & & 6.4 \\
\hline Elementos & La & 1,550 & & 1,29 & & \\
\hline Terras & $\mathrm{Ce}$ & 2,990 & & 2,330 & & \\
\hline Raras & Nd & 2,290 & & 1,200 & & \\
\hline & $\mathrm{Sm}$ & 0,480 & & 0,486 & & \\
\hline & Eu & 0,140 & & 0,110 & & \\
\hline & Gd & 0,300 & & 0,580 & & \\
\hline & Dy & 0,420 & & 0,576 & & \\
\hline & Ho & 0,098 & & 0,150 & & \\
\hline & Er & 0,270 & & 0,300 & & \\
\hline & $r_{b}$ & 0,360 & & 0,360 & & \\
\hline & Lu & 0,052 & & 0,06 & & \\
\hline & $\Sigma$ TRL & 7,310 & & 5,300 & & \\
\hline & $\Sigma$ TRP & 1,500 & & 2,028 & & \\
\hline & $\mathrm{E} u / \mathrm{Eu}^{*}$ & 1,05 & & 0,63 & & \\
\hline & $(\mathrm{La} / \mathrm{Yb}) \mathrm{N}$ & 2,90 & & 2,41 & & \\
\hline & $(\mathrm{L} a / \mathrm{Sm}) \mathrm{N}$ & 2,03 & & 1,69 & & \\
\hline & $(\mathrm{Gd} / \mathrm{Yb}) \mathrm{N}$ & 0,67 & & 1,29 & & \\
\hline
\end{tabular}

GEOLOGIA ESTRUTURAL Neste trabalho procurouse realizar uma análise estrutural baseada, principalmente, nos critérios geométricos e de superimposição de estruturas. Dentro deste enfoque, os diferentes conjuntos de estruturas foram hierarquizados em três fases de deformação, o que não implica no mesmo número de eventos deformativos.

Pomerene (1964) refere-se a uma discordância angular entre as rochas do Grupo Nova Lima, na faixa de Piedade do Paraopeba, e as rochas do Supergrupo Minas na Serra da Moeda. De fato, especialmente na porção norte da faixa, a superfície $\mathrm{S}_{0}$ nos metassedimentos do Grupo Nova Lima mostra uma orientação em tomo de E-W. Esta superfície foi transposta e, parcialmente, reorientada segundo N-S, que é a direção do Supergrupo Minas na Serra da Moeda. Portanto a estruturação original do Grupo Nova Lima segundo E-W é anterior ao evento que gerou a estruturação N-S dominante na área.

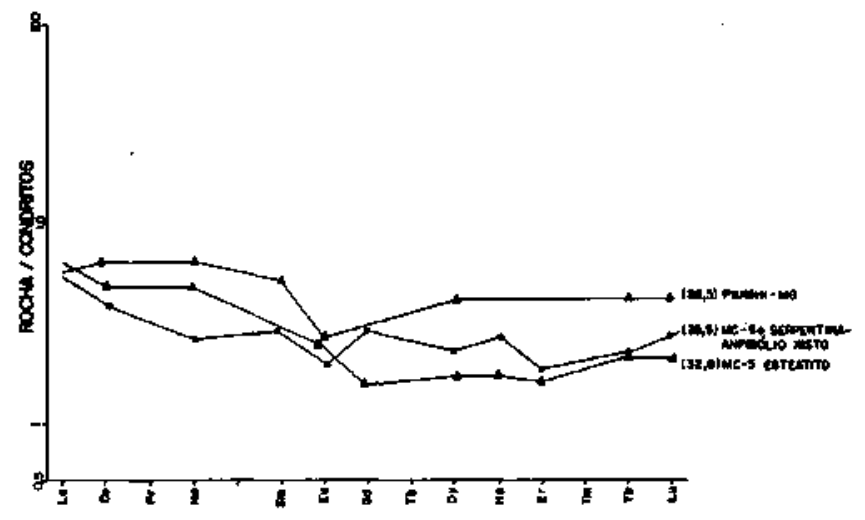

Figura 3 - Padrão de elementos terras-raras dos metakomaíiitos de Piedade do Paraopeba (amostras MC-5 e MC-5A) e metakomatiito de Pium-hi (Jahn \& Schrank 1983). Números entre parênteses indicam $\% \mathrm{MgO}$

Figure 3 - REE pattern for Piedade do Paraopeba metakomatiites (samples MC-5 and MC-5a) and for Pium-hi metakomatiite (Janh and Schrank 1983). Numbers in blackets show $\% \mathrm{MgO}$

Fase $D_{n}$ A fase de deformação $\mathrm{D}_{\mathrm{n}}$ foi responsável pelo empilhamento tectônico, por cavalgamentos, das unidades maiores da área. Isto resultou em uma estrutura imbricada, onde a faixa do Grupo Nova Lima aparece como uma escama de empurrão posicionada entre o Complexo Bonfim e o Supergrupo Minas. Esta interpretação da estruturação da faixa Nova Lima é concordante com a de Pires (1979). Esta escama acunha para sul, onde o Quartzito Moeda passa a posicionar-se diretamente sobre os gnaisses. Todos os contatos entre as grandes unidades são de caráter tectônico. Entre o Quartzito Moeda e os gnaisses ocorre uma faixa milonítica de até algumas dezenas de metros de espessura. $\mathrm{O}$ quartzito mostra evidências de que o movimento tectônico deu-se, preferencialmente, segundo as superfícies de acamamento. Nestas superfícies observa-se o crescimento orientado de fibras de quartzo (fibres de remplissage segundo Nicolas 1984), que constituem elementos úteis na determinação da direção e sentido dos movimentos finais do cavalgamento. Em lâmina delgada, o quartzito apresenta texturas que evidenciam estágios diferentes de milonitização. Em um estágio mais parcial, grãos maiores de quartzo são preservados como porfiroclastos, com bordos recristalizados (Prancha $\mathrm{lF}$ ). Com o avanço da deformação a cominuição dos grãos é quase total, e a rocha apresenta marcante orientação definida por grãos de quartzo muito estirados, mas ainda identificáveis, a despeito da recristalização posterior. Nos milonito-gnaisses são comuns os porfiroclastos de quartzo, mais raro e de feldspato, exibindo caudas assimétricas de fino material recristalizado (Prancha $\mathrm{IE}$ ). As faixas miloníticas no Complexo Gnáissico-Granitóide não se restringem à zona de contato, sendo freqüentes zonas de cisalhamento estreitas no interior do Complexo. Os milonito-gnaisses mostram graus variáveis de recristalização pós-cinemática. No contato Quartzito Moeda/Xisto Nova Lima a milonitização dos quartzitos foi mais discreta, possivelmente devido ao comportamento mais dúctil das rochas xistosas. $\mathrm{O}$ contato entre gnaisses $\mathrm{e}$ xistos do Grupo Nova Lima encontra-se, via de regra, encoberto, mas os gnaisses estão mais ou menos milonitizados próximo ao contato, exibindo uma foliação milonítica que paraleliza a superfície de contato e a foliação principal $\left(\mathrm{S}_{\mathrm{n}}\right)$ nos xistos. $\mathrm{Na}$ região de Piedade do Paraopeba os xistos estão em contato com um gnaisse exibindo textura augen. Adicionalmente, não se encontram evidências de que as fases granitóides mais novas do Complexo, pouco foliadas, atinjam o Grupo Nova Lima. Entretanto, datações U-Pb demonstraram que estes granitóides podem ser mais novos que o vulcanismo do Grupo Nova Lima 
(Machado et al. 1989), o que reforça a hipótese de um posicionamento alóctono da faixa greenstone por sobre o Complexo Gnáissico-Granitóide de Bonfim.

Diversas estruturas lineares ( $\mathrm{Ln}$ ) se prestam como indicadoras da direção de transporte tectônico. Estas são: seixos estírados no conglomerado basal da Formação Moeda; fibras de quartzo orientadas na superfície de acamamento do Quartzito Moeda; porfiroclastos estirados no milonito-gnaisse; lineação de crescimento mineral. A direção fornecida pela lineação de estiramento/mineral situa-se entre E-W e ESE-WNW (Fig. 4b). O sentido do movimento tectônico, deduzido da assimetria das caudas de porfiroclastos, relação entre superfícies S-C, e pela orientação de shear bands é, predominantemente, para oeste. Entretanto, indicações de movimentos em sentido oposto foram também observados.

Associada à fase $D_{n}$ desenvolve-se a principal estrutura planar das rochas do Grupo Nova Lima, a xistosidade $\mathrm{S}_{\mathrm{n}}$. Nos xistos máficos/ultramáficos Sn pode ser caracterizada como uma superfície de transposição, preservando em raras charneiras de microdobras restos de um bandamento mais antigo. Admitindo-se que parte destas rochas teria estrutura original em almofada, este bandamento composicional que paraleliza e/ ou é transposto por $S_{n}$ poderia ter resultado do rearranjo tectônico dessa estrutura primária. No Quartzito Moeda, a $S_{n}$ pode estar muito pobremente desenvolvida, ou então ocorre como uma foliação milonítica em estreitas zonas de cisalhamento. A dispersão dos pólos de $\mathrm{S}_{\mathrm{n}}$ no Grupo Nova Lima (Fig. 4a) reflete os redobramentos posteriores, $D_{n+1}$ e $D_{n+2}$.

Dobras relativas à fase $D_{n}$ são raras, em geral representadas pelas microdobras do Xisto Nova Lima já citadas, além de dobras centimétricas intrafoliais nos itabiritos. São dobras apertadas a isoclinais e a direção de charneira parece tender ao paralelismo com a direção de transporte tectônico.

Fase $D_{n+7}$ A esta fase se associam dobras com charneiras orientadas, preferencialmente, para E-NE e duas superfícies de clivagem $\left(\mathrm{S}_{\mathrm{n}+1}\right.$ e $\left.\mathrm{S}_{\mathrm{n}+\mathrm{la}}\right)$. As dobras $\mathrm{D}_{\mathrm{n}+1}$ variam de ondulações (Fig. 5a) a dobras mais apertadas. Nos itabiritos podem apresentar charneiras angulares. Dobras $\mathrm{D}_{\mathrm{n}+1}$, com amplitudes de 1 a $2 \mathrm{~km}$, são facilmente identificáveis em planta ao longo do flanco do Sinclinal Moeda.

As clivagens $\mathrm{S}_{\mathrm{n}+1}$ e $\mathrm{S}_{\mathrm{n}+\mathrm{la}}$ exibem máximos de, respectivamente, 36/90 e 153/57 (Figs. 4c e 4d). As lineações definidas pela interseção entre $S_{n+1} / S_{n}$ e $S_{n+1 a} / S_{n}$, e também pela interseção $\mathrm{S}_{\mathrm{n}+1} / \mathrm{S}_{\mathrm{n}+\mathrm{l}}$, mostram valores coincidentes em torno de 120/60 (Fig. 4e). Ao se desdobrar a estrutura da Serra da Moeda (fase $D_{n+2}$ ), $S_{n+1}$ e $S_{n+1 a}$ assumem uma mesma direção em torno de N70W, mergulhando para quadrantes opostos e fazendo entre si um ângulo próximo de $90^{\circ}$, tendo a superfície $S_{n}$ como plano bissetor. Esta situação assemelha-se ao caso das clivagens de crenulação conjugadas descritas por Rickard (1961). Na região do Pico do Itabirito, flanco leste do Sinclinal Moeda, Rosiére (1982) descreve um par de "xistosidades transversais conjugadas" que parecem correlatas a $S_{n+1}$ e $S_{n+1 a}$.

Ambas as superfícies de clivagem não se desenvolvem, necessariamente, em um mesmo afloramento, e caracterizamse por uma distribuição muito irregular. A clivagem $S_{n+1}$ tende a ser mais penetrativa, em especial em xistos e filhos. A interseção desta superfície com $\mathrm{S}_{\mathrm{n}}$ gera uma lineação muito característica $\left(\mathrm{L}_{\mathrm{n}+\mathrm{I}}\right)$, pois resulta uma pencil structure. A clivagem $\mathrm{S}_{\mathrm{n}+\mathrm{la}}$ mostra, em geral, morfologia de clivagem de fratura com espaçamento variável. Eventualmente, associa-se a uma crenulação pouco acentuada da superfície $S_{n}$.

Fase $D_{n+2}$ As dobras $\mathrm{D}_{\mathrm{n}+2}$ em escala mesoscópica variam de ondulações a dobras mais apertadas, mas com ângulo apical geralmente superior a $90^{\circ}$ (Fig. 5b). São dobras isópacas, evidenciando um dobramento do tipo flexural. Associa-se a essas dobras uma clivagem plano-axial $\mathrm{S}_{\mathrm{n}+2}$, cuja morfologia varia em função do tipo rochoso. Nos quartzitos, a superfície

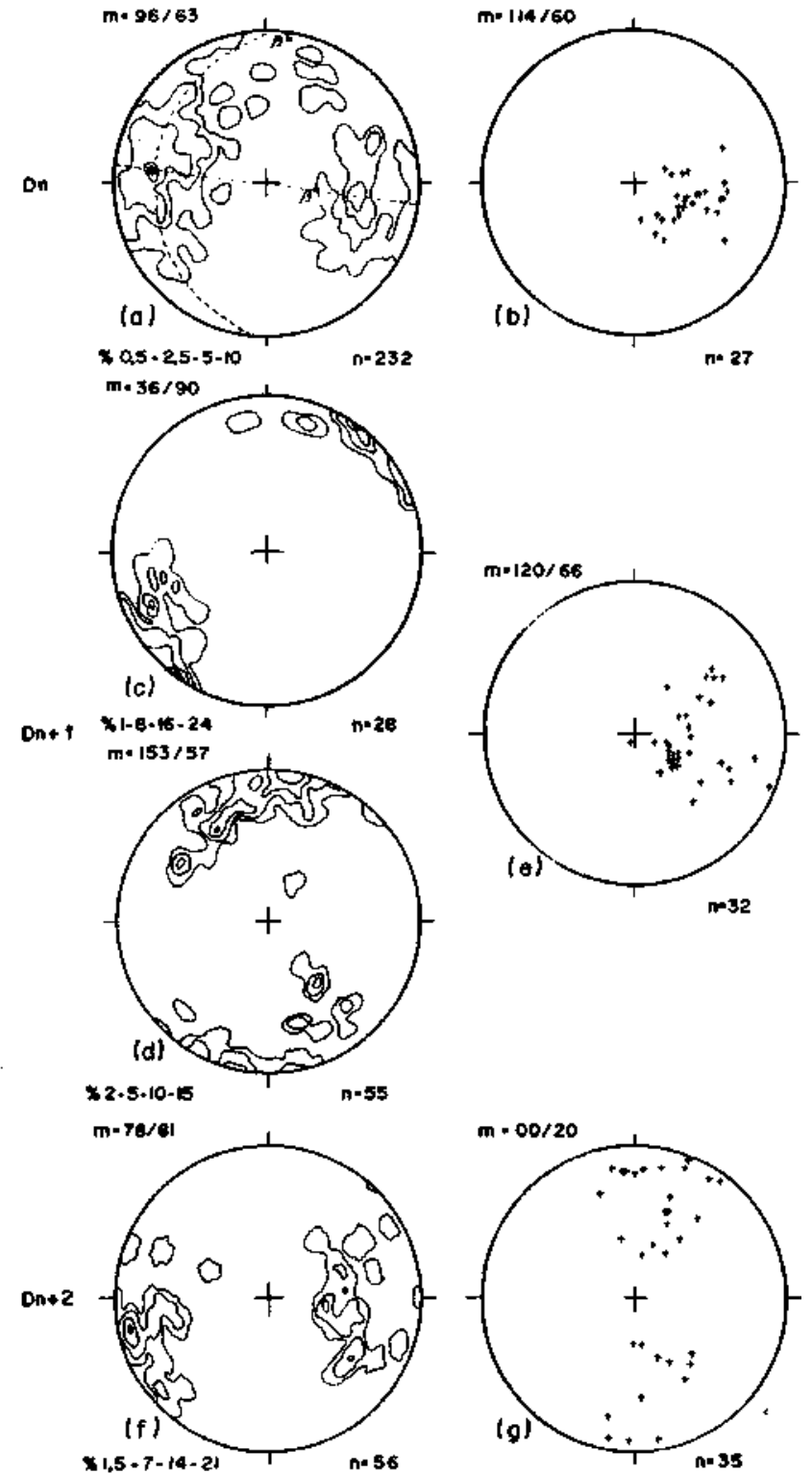

Figura 4 - Diagramas Schmidt-Lambert para os elementos estruturais planares e lineares. A. foliação principal no Grupo Nova Lima $\left(S_{n}\right)$ - os dois eixos beta $\left(\beta{ }^{\prime}=88 / 62\right.$ e $\left.\beta "=08 / 00\right)$ refletem, respectivamente, os dobramentos $D_{n+1}$ e $\mathrm{D}_{\mathrm{n}+2} ; \boldsymbol{B}$. lineação mineral e de estiramento $L_{n} ; \boldsymbol{C}$. foliação $5_{\mathrm{n}+} ; \boldsymbol{D}$. foliação $S_{n+l a} ; \boldsymbol{E}$. lineação de crenulação, lineação de interseção, eixo de dobra $L_{n+1} ; \boldsymbol{F}$. foliação $S_{n+2} ; \boldsymbol{G}$. lineação de crenulação e interseção $L_{n+2} ; n=$ número de medidas; $m$ = máximo calculado

Figure 4 - Equal area plots showing the planar and linear structures. A. main foliation for the Nova Lima Group $\left(\mathrm{S}_{\mathrm{n}}\right)$, the two axes $(\beta \prime=88 / 62$ and $\beta "=08 / 00)$ are related, respectively, to folding events $\mathrm{BD}_{\mathrm{n}+1}$ and $\mathrm{D}_{\mathrm{n}+2} ; \mathbf{B}$. Ln stretching and mineral 73 lineation; C. $\mathrm{S}_{\mathrm{n}+1}$, foliation; D. $\mathrm{S}_{\mathrm{n}+1 \mathrm{a}}$ foliation; E. $\mathrm{L}_{\mathrm{n}+1}$, lineations and fold axes; $\mathbf{F}$. $\mathrm{S}_{\mathrm{n}+2}$ foliation; $\mathbf{G}$. $\mathrm{L}_{\mathrm{n}+2}$ lineation. $\mathrm{n}=$ number of measurements and $\mathrm{m}=$ calculated maximum

$\mathrm{S}_{\mathrm{n}+2}$ se apresenta como uma clivagem de fratura bastante espaçada, enquanto nas rochas xistosas $\mathrm{S}_{\mathrm{n}+2}$ evolui da simples crenulação da superfície principal $\mathrm{Sn}$ até uma clivagem de crenulação apertada, com transposição parcial de $\mathrm{S}_{0}$. Não se observa crescimento mineral segundo $S_{n+2}$, mas a superfície de clivagem pode ser marcada por concentrações de opacos, representando o resíduo insolúvel dos processos de dissolução 
por pressão atuantes na geração da clivagem. No conjunto da área, o desenvolvimento da clivagem $\mathrm{S}_{\mathrm{n}+2}$ e da lineação de crenulação $\mathrm{L}_{\mathrm{n}+2}$ é irregular.

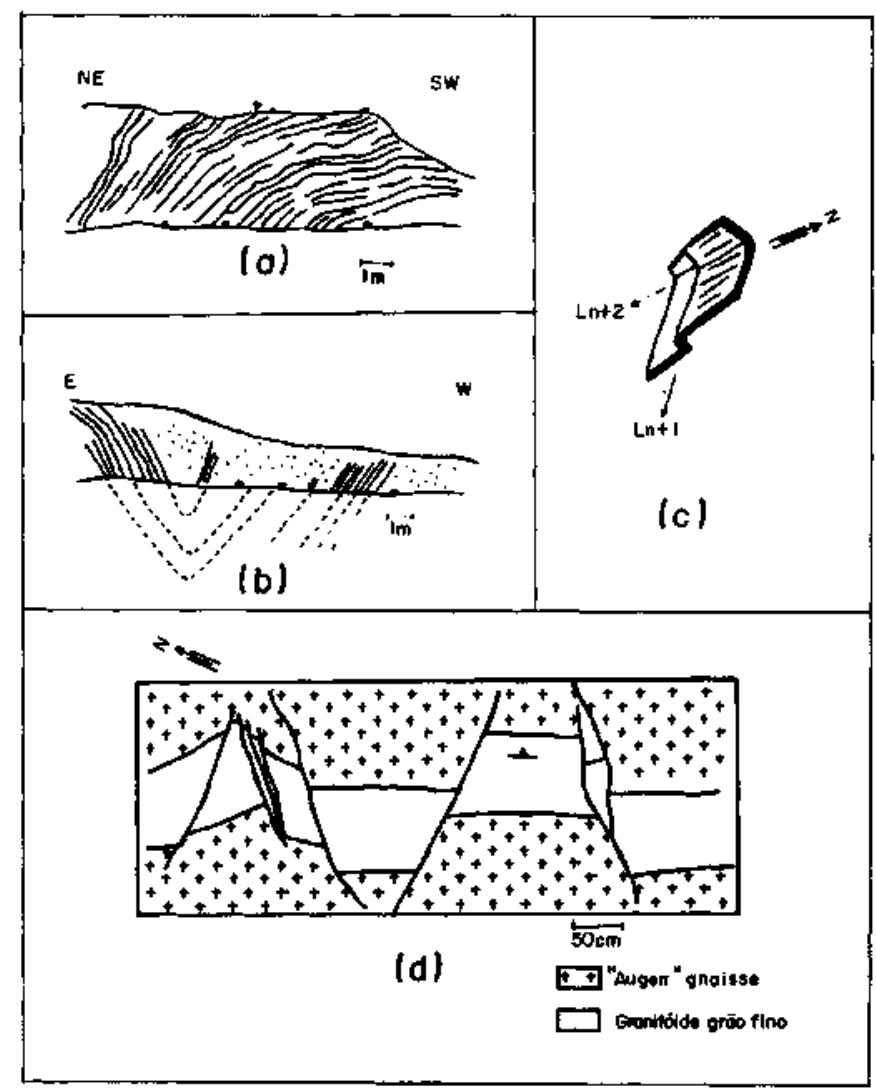

Figura 5 - Exemplos de estruturas observadas. A. dobra aberta e ondulações $\mathrm{D}_{\mathrm{n}+1}$ no itabirito da Formação Cauê, Supergrupo Minas; $\boldsymbol{B}$. niveis de formação ferrifera em xisto decomposto, Grupo Nova Lima, exibindo dobras $\mathrm{D}_{\mathrm{n}+2} ; \boldsymbol{C}$. interferência de dobras $D_{n+1}$ e $D_{n+2}$, observado em corte da estrada de Piedade do Paraopeba; D. padrão das zonas rúpteis tardias

Figure 5 - Examples of structures. A. Cauê Formation itabirite showing a $D_{n+1}$ open fold and undulations; B. Nova Lima Group iron formation interlayered with weathered schists, showing $D_{n+2}$ folds; C. $D_{n+1}$, fold refolded by a $D_{n+2}$ fold; D. Late brittle zones

A distribuição de $\mathrm{S}_{\mathrm{n}+2}$ em estereograma (Fig. 4f) revela um leque com direção em torno de N-S. Os mergulhos são elevados a subverticais. Os eixos de dobra, crenulação e interseção $\mathrm{S}_{\mathrm{n}+2} / \mathrm{S}_{\mathrm{n}}$ direcionam-se segundo o meridiano (Fig. $4 \mathrm{~g}$ ). A variação dos caimentos, de horizontais até $60^{\circ}$, deve refletir o fato do dobramento $\mathrm{D}_{\mathrm{n}+2}$ afetar uma superfície previamente dobrada.

As estruturas da fase $D_{n+2}$ se mostram congruentes com a grande estrutura do Sinclinal Moeda, sugerindo que esta teria se formado nessa fase. Ladeira \& Viveiros (1984) e Chemale et al. (1990), partindo de uma análise global da estruturação do Quadrilátero Ferrifero, apresentam modelos alternativos a este. Embora essencialmente diferentes, os dois modelos referidos consideram o Sinclinal Moeda uma estrutura precoce na evolução tectônica do Quadrilátero Ferrifero, na qual foram impressas as deformações subseqüentes. Ainda que os dados apresentados neste trabalho apontem o Sinclinal Moeda como uma estrutura tardia na evolução estrutural da área, estes não são suficientes para excluir outras interpretações face ao caráter restrito da área investigada.
Associado à fase $\mathrm{D}_{\mathrm{n}+2}$ tem-se o desenvolvimento de zonas rúpteis de alto ângulo, com direção NE-SW e SE-NW, que cortam transversalmente o flanco do Sinclinal Moeda. Estas mesmas zonas rúpteis, em escala de afloramento, podem ser observadas cortando o Complexo Gnáissico (Fig. 5d).

CONCLUSÕES A variação faciológica, constatada no Grupo Nova Lima, sugere a existência, a sul da faixa, de um centro de vulcanismo, que poderia ter apresentado uma certa ciclicidade ultramáfica-máfica-félsica. Entretanto, a ausência de critérios de topo e base, e a intensa transformação sofrida pelas rochas, impede a correta identificação e caracterização destes ciclos. A proposição de sua existência, todavia, é reforçada por analogia com outras seqüências tipo greenstone belt arqueanas no mundo. A parte norte da seqüência representaria uma fácies distal do centro vulcânico. É composta, predominantemente, por sedimentos pelíticos e psamo-pelíticos, encerrando bancos arenosos com contribuição vulcanoclástica.

Apesar do número reduzido de amostras de rochas metavulcânicas analisadas, demonstra-se que os processos de alteração afetaram as características químicas originais das rochas. Porém, os padrões das assinaturas dos elementos terras raras apresentam feições similares a rochas komatiíticas metamorfoseadas e alteradas por processos metassomáticos. Estas características, aliadas a feições de campo, permitem definir a seqüência ultramáfica-máfica como vulcanogênica. 3. O entendimento da evolução estrutural da área é dificultado pelas dúvidas em relação a um aspecto essencial, qual seja, as relações com a estrutura NE da Serra do Curral, a norte. Extensos cavalgamentos marcam o primeiro evento deformacional a atingir conjuntamente as unidades Rio das Velhas e Minas, caracterizado neste trabalho como fase $D_{n}$. A fase de deformação $D_{n}$, com direção de transporte tectônico entre EW e ESE-WNW, foi responsável pela estrutura imbricada da área. Existem evidências de que a faixa do Grupo Nova Lima mostrava uma estruturação inicial em torno de E-W, sofrendo, posteriormente, a superimposição das estruturas N-S da fase $D_{n}$. É discutível se as estruturas englobadas na fase $D_{n+1}$ (dobras com charneiras preferencialmente mergulhando para E-NE e o par conjugado de clivagens) foram geradas em um evento deformativo distinto, ou estão associadas à deformação $\mathrm{D}_{\mathrm{n}}$, de caráter rotacional progressivo. Para Rosiére (1982), as clivagens conjugadas relacionam-se à primeira deformação. Neste caso as dobras $D_{n+1}$, com charneiras aproximadamente paralelas à direção de transporte tectônico, deveriam ser interpretadas como dobras da classe "a" (Mattauer 1975). Segundo Malavieille (1987), o melhor mecanismo de formação destas dobras parece ser através da reorientação de dobras formadas obliquamente durante uma deformação progressiva. A deformação final a atingir a área gerou as estruturas N-S da fase $\mathrm{D}_{\mathrm{n}+2}$ e as zonas rúpteis NE-SW e SE-NW.

Um dos corpos de metavulcanitos félsicos foi datado pelo método U-Pb em zircão (Machado et al, 1989). A idade de cristalização obtida para a rocha foi de $2.772 \pm 6 \mathrm{Ma}$. A análise de uma segunda fração e um núcleo individual forneceram, respectivamente, as idades mínimas de 2.883 $\pm 6 \mathrm{Ma}$ e $2.912 \mathrm{Ma}$. A presença deste zircão herdados é indicativa da existência de crosta siálica anterior à deposição do Grupo Nova Lima. Por outro lado, um granitóide milonitizado em contato tectônico com o Quartzito Moeda, a sul da área estudada, foi datado em $2.730 \pm 10 \mathrm{Ma}$. Este corpo pode estar relacionado ao final da evolução arqueana do greenstone belt.

Agradecimentos Este trabalho contou com a participação dos estudantes de graduação (1988) Senira da Silva Kattah (bolsista BK-CNPq), Helena Beatriz Guimarães (bolsista BIC$\mathrm{CNPq}$ ) e Marcus Guarieiro, a quem agradecemos a valiosa contribuição. Os recursos foram provenientes do CNPq (pró- 
cesso $n^{\circ} .40 .5378 / 87.4$, C.M.N.), CPq-UFMG (processos $n^{\text {os }}$ 23072.050826/88-41 e 23072.029011/80.01, C.M.N.) e CNPq (processo $n^{\circ} 40.2302 / 89$ E.A.L. e $n^{\circ} 40.0949 / 89-0$ S.O.P.). Agradecemos também à RODIMINAS, na pessoa de seu sócio, eng. Luis Carlos Villani, a cortesia pelo oferecimento de mora- dia e acesso à área da Mina do Carrapato, de propriedade daquela companhia, durante parte dos trabalhos de campo e ao sr. J. Diniz, encarregado, pela sua cordial atenção. Somos gratos a dois revisores anônimos que muito contribuíram para a melhoria do manuscrito original.

\section{REFERÊNCIAS BIBLIOGRÁFICAS}

CHEMALE, F., Jr.; ROSIÈRE, C.A.; ENDO, 1.1990. Quadrilátero Ferrifero evolução monocíclica ou policíclica. In: CONOR. BRAS. GEOL., 36. Natal, 1990. Boletim de Resumos... Natal, SBG. p. 294-295.

CONDIE, K.C. 1981. Archean Greenstone Belts. Amsterdan, Elsevier. 434 p.

DORR, JVN III POMERENE, J.B. RYNEARSON, G.A. 1957 Revisão da Estratigrafia Pre-Cambriana do Quadrilátero Ferrifero, Brasil. DNPM/DFPM. 31 p. (Avulso 81).

DRAKE, A.A. \& MORGAN, B.A. 1980. Precambrian Plate Tectonics in the Brazilian Shield - Evidence from the Pré-Minas Rocfcs of the Ouadrilátero Ferrifero, Minas Gerais. USA, U.S. Geol. Survey. 19 p. (Prof. Paper 1119B).

EVENSEN, N.M.; HAMILTON, P.J.; O'NIONS, R.K. 1978. Rare earth abundances in chondritic meteorites. Geoch. Cosmoch. Acta, 42:1199-1212.

GAIR, J.E. 1962. Geology and Ore Deposits of the Nova Lima and Rio Acima Quadrangles, Minas Gerais, Brazil. USA, U.S. Geol. Survey. 67 p. (Prof. Paper 341 A).

GODOY, M.P. 1957. A Expressão Econômica do Vale do Rio Paraopeba. Belo Horizonte, DAEE. $149 \mathrm{p}$

GUIMARÃES, H.B.; GUAR1EJRO, M.; KATTAH, S.S. 1988. Mapeamento Geológico da Regiáo de Piedade do Paraopeba, com Enfase ao Estudo Petrológico das Seqüências Metavulcânicas Básicas e Ultrabásicas do Supergrupo Rio das Velhas. Belo Horizonte, IGC-UFMG. 137 p. (Trabalho de Graduação)

IGA. 1982. Mapeamento geológico da região metropolitana de Belo Horizonte - Folha Brumadinho escala 1:50.000. Belo Horizonte, IGA.

JAHN, B. \& SCHRANK, A. 1983. REE geochemistry of komatiite and associated rocks from Pium-hi, Southeastern Brazil. Precamb. Res., 21:1-20.

LADEIRA, E.A. 1980. Metallogenesis of Gold at the Morro Velho Mine and in the Nova Lima District, Quadrilatero Ferrifero, Minas Gerais, Brazil. London. 272 p. (PhD Thesis, University of Western Ontario)

LADEIRA, E. A. 1981. Primeiras lavas com almofadas ("pillows") encontradas no Supergrupo Rio das Velhas, de idade arqueana, no Quadrilátero Ferrifero e no Distrito de Pitangui, Minas Gerais. Ciências da Terra, 1(1): $12-14$

LADEIRA, E.A. 1988. Metalogenia dos depósitos de ouro do Quadrilátero Ferrifero, Minas Gerais. In: SCHOBBENHAUS, C. \& COELHO, C.E.S. eds. Principais Depósitos Minerais do Brasil. 3d. v. HI. Brasilia, DNPM. p. 301-375.

LADEIRA, E.A.; CARDOSO, R.N.; CASTRO, F.D.; FONSECA, S.G. 1985. Relatório dos Trabalhos de Pesquisa de Serpentinito e Ouro nos Locais Denominados Ipê, Município de Brumadinho. Minas Gerais, Rodominas Ind. Ltda. 79 p. (Relatório Interno, 2 v, 16 Fig.)

LADEIRA, E.A.; ROESER, H.M.P.; TOBSCHALL, H.J. 1983. Evolução petrogenética do Cinturão de Rochas Verdes Rio das Velhas, Quadrilátero Ferrifero, Minas Gerais. In: SIMP. GEOL. MINAS GERAIS, 2. Belo Horizonte, 1983. Anais... Belo Horizonte, SBG/MG. p. 149-165. (Boletim 3).
LADEIRA, E.A. \& VIVEIROS, J.F.M. 1984. Hipótese sobre a Estruturação do Quadrilátero Ferrifero com Base nos Dados Disponíveis. Belo Horizonte, SBG-MG. 19 p. (Boletim 4).

LYRIO, J.G.G. 1977. Prospecção e Pesquisa de Ouro. Ouro Preto, SICEG. p. 57-92 (Boletim 17)

MACHADO, N.; NOCE, C.M.; OLIVEIRA, O.A.B; LADEIRA, E.A. 1989. Evolução geológica do Quadrilátero Ferrifero no Arqueano e Proterozóico Inferior com base em geocronologia U-Pb. In: SIMP. GEOL. MINAS GERAIS, 5. Belo Horizonte, 1989. Anais... Belo Horizonte, SBG-MG. p. 1-55. (Boletim 10).

MALAVIEILLE ,J. 1987. Extensional shearing deformation and kilometerscale "a"-type folds in a cordilleran metamorphic core complex (Raf River Mountains, Northwestern Utah). Tectonics, 6(4): 423-448.

MATTAUER, M. 1975. Sur le mécanisme de formation de Ia schistosité dans 1'Himalaya. Earth Plan. Sci. Let., 28:144-154.

NESBITT, R.W. \& SUN, S.S. 1976. Geochemistry of Archean spinifex-textured peridotites and magnesian and low magnesian tholeites. Earth Plan. Sci. Let., 31:433-453.

NICOLAS, A. 1984.Principes de Tectonique. Paris, Masson. $196 \mathrm{p}$

PIRES, F.R.M. 1979. Structural Geology and Stratigraphy at the Junction of the Curral Anticline and the Moeda Syncline, Quadrilátero Ferrifero, Minas Gerais, Brazil. Michigan. 220 p. (PhD Thesis, Michigan Technological University)

POMERENE, J.B. 1964. Geology and Ore Deposits of the Belo Horizonte, Ibirite and Macacos Quadrangles, Minas Gerais, Brasil. USA, U.S Geol. Survey. 58 p. (Prof. Paper 34 ID).

RICKARD, M.J. 1961. A note on cleavages in crenulated rocks. Geol. Mag., 98(4):324-332.

ROSIËRE, C.A. 1982. Analise estructural del cuerpo mineral de hierro del yacimiento del "Pico del Itabirito", Quadrilátero Ferrifero, Minas Gerais, Brasil. In: CONGR. LATINOAMERICANO GEOL., 5. Buenos Aires, 1982. Anales... Buenos Aires, actas IV, p. 351-368.

SCHORCHER, H.D. 1978. Komatiitos na estrutura Greenstone Belt, Série Rio das Velhas, Quadrilátero Ferrifero, Minas Gerais, Brasil. In: CONGR. BRAS. GEOL., 30. Recife, 1978. Boletim de Resumos... Recife, SBG. p. 292-293.

SUN, S.S. \& NESBITT, R.W. 1978. Petrogenesis of Archean ultrabasic and basic volcanics: evidence from rare earth elements. Contrib. Mineral. Petrol., 65:301-325.

WICKS, F.J. \& WHITTAKER, J.W. 1977. Serpentine textures and serpentinization. Can. Mineral, 15:459-488.

MANUSCRITO A691 Recebido em 5 de fevereiro de 1991 Revisão do autor em 14 de abril de 1992 Revisão aceita em 13 de maio de 1992 